\title{
Assessment of Maximum Bite Force in Oral Submucous Fibrosis Patients: A Preliminary Study
}

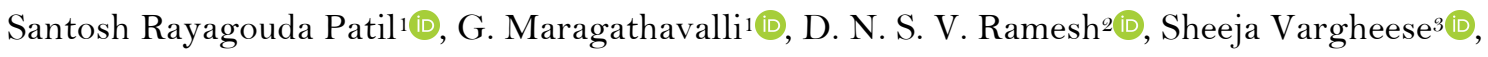 \\ Ibrahim A. Al-Zoubi ${ }^{4}\left(\mathbb{D}\right.$, Mohammad Khursheed Alam ${ }^{5}$ (D)
}

\begin{abstract}
${ }^{1}$ Department of Oral Medicine and Radiology, Saveetha Dental College and Hospitals, Chennai, India. 2Department of Oral Medicine and Radiology, A. M. E’S Dental College and Hospital, Raichur, India. ${ }^{3}$ Department of Periodontology, Saveetha Dental College and Hospitals, Chennai, India.

${ }^{4}$ Department of Preventive Dentistry, College of Dentistry, Jouf University, Kingdom of Saudi Arabia. ${ }^{5}$ Department of Orthodontics, College of Dentistry, Jouf University, Kingdom of Saudi Arabia.
\end{abstract}

Author to whom correspondence should be addressed: Dr. Santosh R. Patil, Department of Oral Medicine and Radiology, Saveetha Dental College and University, Chennai, India. Phone: +919113075740. E-mail: drpsantosh@,gmail.com.

Academic Editors: Alessandro Leite Cavalcanti and Wilton Wilney Nascimento Padilha

Received: 30 April 2019 / Accepted: 29 October 2019 / Published: 06 November 2019

How to cite this article: Patil SR, Maragathavalli G, Ramesh DNSV, Vargheese S, Al-Zoubi IA, Alam MK. Assessment of maximum bite force in oral submucous fibrosis patients: a preliminary study. Pesqui Bras Odontopediatria Clín Integr. 2020; 20:e4871. https://doi.org/10.1590/pboci.2020.009

\begin{abstract}
Objective: To determine the maximum bite force (MBF) in oral submucous fibrosis (OSMF) patients and to compare them with that of healthy subjects. Material and Methods: Twenty patients who were clinically confirmed, as OSMF and 20 healthy controls matched for age, gender, and number of intact functional teeth were included in this study. For each subject, age, gender, weight, height and body mass index (BMI) were recorded. The MBF registration was carried out by the two evaluators, who were previously calibrated. Bite force was measured in the first molar region using a force transducer occlusal force meter for each subject seated at the upright position, with Frankfort's plane nearly parallel to the floor, and no head support. The Student's independent t-test was used to determine the statistical significance in relation to mean height, weight, BMI and the presence of number of intact teeth and MBF between the healthy subjects and OSMF individuals. A comparison of grades of OSMF with all variables was carried out by one-way ANOVA test. Results: No significant difference was found in mean age, mean height, weight, BMI and the presence of the number of intact teeth between healthy individuals and OSMF patients. The mean MBF in healthy subjects was $628.23 \pm 24.39 \mathrm{~N}$ and $635.47 \pm 31.22 \mathrm{~N}$ in OSMF patients. Even though the healthy subjects reported a higher MBF than OSMF patients did, the difference was statistically non-significant. With regards to sides, no significant difference was observed in mean MBF in healthy subjects and OSMF patients on the right $(\mathrm{p}=0.7818)$ and left side $(\mathrm{p}=0.6154)$. Conclusion: The healthy subjects reported higher MBF values than OSMF patients did and the difference was statistically non-significant.
\end{abstract}

Keywords: Dental Occlusion; Bite Force; Stomatognathic Diseases; Oral Submucous Fibrosis. 


\section{Introduction}

Oral submucous fibrosis (OSMF) is a chronic disease of insidious onset of unknown etiology affecting the oral and oropharyngeal region characterized by progressive fibrosis of oral submucous. OSMF is regarded as a disease of collagen metabolic disorder showing excessive collagen synthesis along with reduced collagen degradation [1].

OSMF is known to be associated with oral epithelial dysplasia and cancer, so it is considered to be a premalignant condition. OSMF affects the oral mucosa along with the pharynx and upper digestive tract. The characteristic features of OSMF are progressive inability to open the mouth, inflammation and progressive fibrosis of the submucosal tissues [2]. This condition is predominantly manifested in the population of the Indian subcontinent and Southeast Asian [3,4]. Areca nut and its products are regarded as the etiological factors along with some other less proven agents. OSMF presents clinically as blanching of the oral mucosa, burning sensation, ulceration, pain, decreased mobility and depapillation of the tongue, depigmentation of the oral mucosa, and progressive reduction of mouth opening. Severe cases of OSMF presents with nasal twang due and difficulty in hearing $[5,6]$.

Maximum bite force $(\mathrm{MBF})$ is primarily related to mastication and is a helpful marker of the functional condition of the masticatory apparatus and the stacking of the dentition. Measuring the MBF is regarded as an essential component in analyzing the functional capacity of muscles of mastication, and also to compare the activity of these muscles between individuals in different experimental conditions [7].

Multiple factors, like the size of the masticatory muscles, dental occlusion, facial morphology, and functional pain, are regarded as the main factors that influence the magnitude of MBF [7]. Changes in the masticatory muscles in OSMF patients have been previously established [8], but the influence of these changes on $\mathrm{MBF}$ in OSMF patients has been not yet established. Hence this study was carried out to determine the $\mathrm{MBF}$ in OSMF patients and to compare with that of healthy subjects.

\section{Material and Methods}

\section{Study Design and Sample}

This cross-sectional study was carried out at A.M.E's Dental College and Hospital, Raichur, India. Twenty patients who were clinically confirmed as OSMF and 20 healthy controls matched for age, gender and number of intact functional teeth was included in this study.

\section{Data Collection}

The OSMF patients were graded according to previous classification [9]. The inclusion criteria's considered in selection of the participant as follows: Angle Class I molar relationship without an anterior or posterior crossbite or open bite; Class 1 facial profile and normal facial height and no history of orthodontic therapy; No missing teeth in the molar region; No pain related with the molars; No heavily restored teeth in the molar region; No gingival inflammation, no periodontal pathology, and absence of mobility of the teeth; No reported systemic disease (chronic arthritis) or apparent facial asymmetry that could influence the registration of bite force; No parafunctional habits, no pathological wearing facits, or any other soft tissue pathologies; No temporomandibular joint dysfunction and no systemic disease that may influence the neuromuscular system (such as Parkinson's disease).

For each subjects, the following data were collected: age (on the day of examination), gender, weight (in kilograms - kg), height (in meters - m) without shoes, body mass index (BMI): which was calculated from the formula: $\mathrm{BMI}=$ Weight $/$ Height $^{2}$; where weight is in kilograms and height is in meters. 
The MBF registration was carried out by the two evaluators, who were previously calibrated. Bite force was measured in the first molar region using a force transducer occlusal force meter (GM10, Nagano Keiki Co. LTD., Tokyo, Japan). Bite force was displayed digitally in Newton. Before recording, each subject was seated at the upright position, with Frankfort's plane nearly parallel to the floor, and no head support. Each patient was instructed to bite as heavy as they could on the bite force device. The maximum bite force value of the three tests, with 45-second rest between tests, was recorded to be the MBF for both right and left sides.

Intra and interobserver reliability were determined by Kappa agreement statistics. The reliability of the measurements was assessed after an interval of 2 weeks by the same investigators re-examining and remeasuring the MBF in 5 participants.

\section{Data Analysis}

The Statistical Package for the Social Sciences (SPSS) for Windows (version 20.0; SPSS, Chicago, IL, USA) was the standard statistical software package used for data analysis and the level of significance was fixed at $\mathrm{p} \leq 0.05$. The Student's independent t-test was used to determine the statistical significance in relation to mean height, weight, BMI and the presence of number of intact teeth and MBF between the healthy subjects and OSMF individuals. A comparison of grades of OSMF with all variables was carried out by one-way ANOVA test.

\section{Ethical Aspects}

Ethical approval for the study was obtained from the A.M.E's Dental College and Hospital and written informed consent was obtained after explaining the study objectives. All procedures were in accordance with the Declarations of Helsinki.

\section{Results}

The results of the kappa values were $0.86 \pm 0.08$ and $0.82 \pm 0.07$ for both intra and inter-examiner reliability, which indicate almost, perfect agreement. A non-significant difference was observed between OSMF and health groups with respect to mean age $(t=-0.7973, p=0.4269)$, weight $(t=-0.1661, p=0.8684)$, height $(\mathrm{t}=1.9270, \mathrm{p}=0.0564)$, BMI $(\mathrm{t}=-1.2617, \mathrm{p}=0.2096)$ and the presence of number of intact teeth $(\mathrm{t}=0.1506$, $\mathrm{p}=0.8805)$ at $5 \%$ level of significance (Table 1$)$.

Table 1. Distribution of subjects according to mean height, weight, BMI and the number of intact teeth present.

\begin{tabular}{|c|c|c|c|c|}
\hline Variables & Groups & Mean \pm SD & t-value & p-value \\
\hline \multirow[t]{2}{*}{ Age } & OSMF Group & $38.32 \pm 5.40$ & -0.7973 & 0.4269 \\
\hline & Healthy Group & $39.07 \pm 4.89$ & & \\
\hline \multirow[t]{2}{*}{ Weight (Kg) } & OSMF Group & $69.40 \pm 6.30$ & -0.1661 & 0.8684 \\
\hline & Healthy Group & $69.60 \pm 6.88$ & & \\
\hline \multirow[t]{2}{*}{ Height (m) } & OSMF Group & $1.72 \pm 0.09$ & 1.9270 & 0.0564 \\
\hline & Healthy Group & $1.69 \pm 0.07$ & & \\
\hline \multirow[t]{2}{*}{ BMI } & OSMF Group & $23.72 \pm 3.57$ & -1.2617 & 0.2096 \\
\hline & Healthy Group & $24.51 \pm 3.21$ & & \\
\hline \multirow[t]{2}{*}{ Number of Intact Teeth } & OSMF Group & $29.65 \pm 2.34$ & 0.1506 & 0.8805 \\
\hline & Healthy Group & $29.60 \pm 1.06$ & & \\
\hline
\end{tabular}


Similarly, no significant difference was observed between OSMF and health groups with respect to mean MBF $(\mathrm{t}=-1.0991, \mathrm{p}=0.2740)$ at the right side and mean MBF $(\mathrm{t}=-1.0007, \mathrm{p}=0.3190)$ at the left side at $5 \%$ level of significance (Table 2 ).

Table 2. Comparison of MBF between the OSMF group and healthy groups on the right and left sides.

\begin{tabular}{cllll}
\hline Sides & \multicolumn{1}{c}{ Groups } & Mean \pm SD & t-value & p-value \\
\hline Right Side & OSMF Group & $630.56 \pm 48.44$ & -1.0991 & 0.2740 \\
& Healthy Group & $641.12 \pm 56.50$ & & \\
Left Side & OSMF Group & $625.90 \pm 18.65$ & -1.0007 & 0.3190 \\
& Healthy Group & $629.82 \pm 23.99$ & & \\
\hline
\end{tabular}

No significant difference was observed between the right side and left sides with respect to mean MBF $(\mathrm{t}=0.6955, \mathrm{p}=0.4881)$ in the OSMF group and mean MBF $(\mathrm{t}=1.4252, \mathrm{p}=0.1567)$ in the healthy group at $5 \%$ level of significance (Table 3 ).

Table 3. Comparison of MBF between right and left sides in the OSMF group and healthy group.

\begin{tabular}{cllcc}
\hline \multicolumn{1}{c}{ Groups } & \multicolumn{1}{c}{ Sides } & Mean \pm SD & t-value & p-value \\
\hline OSMF Group & Right Side & $630.56 \pm 48.44$ & & \\
& Left Side & $625.90 \pm 18.65$ & 0.6955 & 0.4881 \\
Healthy Group & Right Side & $641.12 \pm 56.50$ & & \\
& Left Side & $629.82 \pm 23.99$ & 1.4252 & 0.1567 \\
\hline
\end{tabular}

On Comparison of grades of OSMF with all variables, a non-significant difference between OSMF grades with age, BMI, number of intact teeth and MBF left side scores at $5 \%$ level ( $\mathrm{p}>0.05)$.

Table 4. Comparison of grades of OSMF with all variables by one-way ANOVA test.

\begin{tabular}{|c|c|c|c|c|c|c|}
\hline Variables & Summary & Grade 1 & Grade 2 & Grade 3 & F-value & p-value \\
\hline \multirow[t]{2}{*}{ Age } & Mean & 39.13 & 38.09 & 37.23 & 0.5438 & 0.5835 \\
\hline & $\mathrm{SD}$ & 4.46 & 5.91 & 6.22 & & \\
\hline \multirow[t]{2}{*}{ Weight (Kg) } & Mean & 69.17 & 69.78 & 69.15 & 0.0666 & 0.9356 \\
\hline & $\mathrm{SD}$ & 6.48 & 7.01 & 4.93 & & \\
\hline \multirow[t]{2}{*}{ Height (m) } & Mean & 1.73 & 1.70 & 1.73 & 1.3137 & 0.2768 \\
\hline & $\mathrm{SD}$ & 0.09 & 0.08 & 0.09 & & \\
\hline \multirow[t]{2}{*}{ BMI } & Mean & 23.27 & 24.45 & 23.29 & 0.7586 & 0.4730 \\
\hline & $\mathrm{SD}$ & 3.77 & 3.44 & 3.45 & & \\
\hline \multirow[t]{2}{*}{ Number of Intact Teeth } & Mean & 30.38 & 29.13 & 29.23 & 1.9885 & 0.1463 \\
\hline & $\mathrm{SD}$ & 3.09 & 1.18 & 2.09 & & \\
\hline \multirow[t]{2}{*}{ MBF Right Side } & Mean & 627.81 & 624.50 & 599.95 & 11.2037 & 0.1246 \\
\hline & $\mathrm{SD}$ & 21.97 & 18.04 & 19.31 & & \\
\hline \multirow[t]{2}{*}{ MBF Left Side } & Mean & 620.44 & 627.16 & 633.75 & 2.3318 & 0.1063 \\
\hline & SD & 17.61 & 19.27 & 17.50 & & \\
\hline
\end{tabular}

\section{Discussion}

The bite force is a significant component of chewing function. It is important to measure bite force to assess masticatory muscles function and also to compare muscle activity between subjects in the different experimental situations [7].

Investigations of interocclusal bite force in humans began over 300 years ago [10]. Bite force was found to be different in different populations. It was reported that urban people have lower bite force than 
people living in a primitive way [11]. For example, a population of Eskimos, who were living in a primitive way, were able to produce a bite force of about $1500 \mathrm{~N}$ [9], while the average bite force in western people was about $600-750 \mathrm{~N}[12]$.

It was reported the involvement of the muscles in the fibrosis process and the replacement of the muscle by fibrous tissue [13]. In a previous study, OSMF patients showed varying degrees of muscle changes including atrophy, degeneration and necrosis of fibers. This muscle changes can be a manifestation of the disease, atrophy being secondary to the limited functional activity of the muscles, which is brought about by fibrosis, or whether it is an essential part of the disease process itself [14].

The number of functional teeth present in any person might influence his/her masticatory efficacy; we did not include any individuals with less than 20 functional teeth. The literature shows that $80 \%$ of the total bite force is dispensed at the molar region [15]; therefore, in the present research, MBF was measured at the first permanent molar and the participants were incorporated in this study as per the strict inclusion standards.

In our study, though the healthy subjects reported a higher MBF than OSMF patients did, the difference was statistically non-significant and when sides were compared, no significant difference was observed in mean MBF in healthy subjects and OSMF patients. This is in agreement with that described by other authors, who observed a non-significant difference in the MBF between controls and OSMF subjects $[16]$.

Although it can be postulated that the changes in the masticatory muscle thickness, function and activity in OSMF patients, especially in advanced cases may significantly influence the MBF in these patients, in the present study we did not see any significant change in the MBF in OSMF subjects, this may be due to the limited number of subjects incorporated.

\section{Conclusion}

The healthy subjects reported a higher maximum bite force values than oral submucous fibrosis patients did and the difference was statistically nonsignificant.

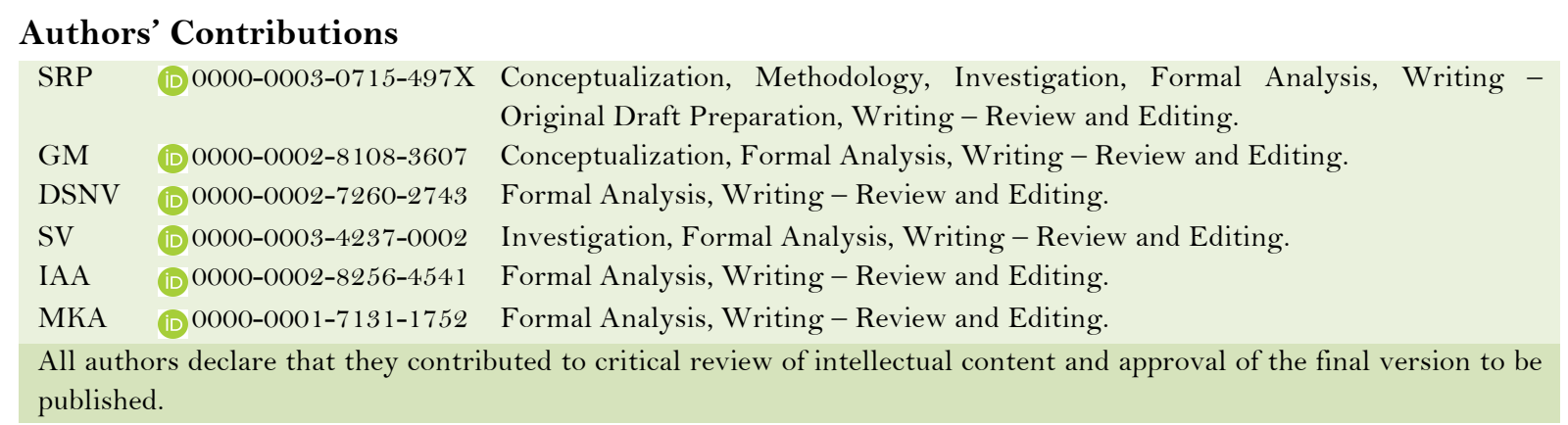

\section{Financial Support}

None.

\section{Conflict of Interest}

The authors declare no conflicts of interest.

\section{References}

[1] Patil S, Khandelwal S, Maheshwari S. Comparative efficacy of newer antioxidants spirulina and lycopene for the treatment of oral submucous fibrosis. Clin Cancer Investig J 2014; 3(6):482-6. 
https://doi.org/10.4103/2278-0513.142618

[2] Patil SR, Yadav Y, Al-Zoubi IA, Maragathavalli G, Sghaireen MG, Gudipaneni RK, et al. Comparative study of the efficacy of newer antioxitands lycopene and oxitard in the treatment of oral submucous fibrosis. Pesqui Bras Odontopediatria Clin Integr 2018; 18(1):e4059. https://doi.org/10.4034/PBOCI.2018.181.67

[3] Patil S, Halgatti V, Maheshwari S, Santosh BS. Comparative study of the efficacy of herbal antioxdants oxitard and aloe vera in the treatment of OSMF. J Clin Exp Dent 2014; 6(3):e265-70. https://doi.org/10.4317/jced.51424

[4] Patil S, Maheshwari S. Proposed new grading of oral submucous fibrosis based on cheek flexibility. J Clin Exp Dent 2014; 6(3):e255-58. https://doi.org/10.4317/jced.51378

[5] Patil S, Santosh BS, Maheshwari S, Deoghare A, Chhugani S, Rajesh PR. Efficacy of oxitard capsules in the treatment of oral submucous fibrosis. J Can Res Ther 2015; 11(2):291-4. https://doi.org/10.4103/0973-1482.136023

[6] Patil S, Doni B, Maheshwari S. Prevalence and distribution of oral mucosal lesions in a geriatric Indian population. Can Geriatr J 2015; 18(1):1 1-4. https://doi.org/10.5770/cgj.18.123

[7] Al-Zarea BK. Maximum bite force following unilateral fixed prosthetic treatment: a within-subject comparison to the dentate side. Med Princ Pract 2015; 24(2):142-6. https://doi.org/10.1159/000370214

[8] El-Labban NG, Caniff JP. Ultrastructural findings of muscle degeneration in oral submucous fibrosis. J Oral Pathol 1985; 14(9):709-17. https://doi.org/10.1111/j.1600-0714.1985.tb00550.x

[9] Khanna JN, Andrade NN. Oral submucous fibrosis: a new concept in surgical management. Report of 100 cases. Int J Oral Maxillofac Surg 1995; 24(6):433-9. https://doi.org/10.1016/s0901-5027(05)80473-4

[10] Uhlig H. On the power of mastication. Dtsch Zahnarztl Z 1953; 8(1):30-45.

[11] Bonjardim LR, Gavião MB, Pereira LJ, Castelo PM. Bite force determination in adolescents with and without temporomandibular dysfunction. J Oral Rehabil 2005; 32(8):577-83. https://doi.org/10.1111/j.1365-2842.2005.01465.x

[12] Hagberg C. Assessments of bite force: a review. J Craniomandib Disord 1987; 1(3):162-9.

[13] Advani DG. Histopathological studies before and after kepacort in oral submucous fibrosis. [Thesis]. University of Bombay; 1982. 83pp.

[14] Sumathi MK, Balaji N, Malathi N. A prospective transmission electron microscopic study of muscle status in oral submucous fibrosis along with retrospective analysis of 80 cases of oral submucous fibrosis. J Oral Maxillofac Pathol 2012; 16(3):318-24. https://doi.org/10.4103/0973-029X.102474

[15] Schieppati M, Di Francesco G, Nardone A. Patterns of activity of perioral facial muscles during mastication in man. Exp Brain Res 1989; 77(1):103-12. https://doi.org/10.1007/bfo0250572

[16] Amarasena JKC, Ariyawardana A, Amarasena N, YamadaY. Mastication and swallowing in patients with oral submucous fibrosis. Asian J Oral Maxillofac Surg 2007; 19(3):145-9.

https://doi.org/10.1016/So915-6992(07)80013-6 